\title{
Value creation dynamics in a project alliance
}

\author{
Farzad Pargar $^{\mathrm{a}, 1}$, Jaakko Kujala ${ }^{\mathrm{a}}$, Kirsi Aaltonen ${ }^{\mathrm{a}}$, Sampsa Ruutu ${ }^{\mathrm{b}}$ \\ ${ }^{a}$ Industrial Engineering and Management, Faculty of Technology, University of Oulu, Oulu, Finland \\ ${ }^{b}$ VTT Technical Research Centre of Finland, Finland
}

\begin{abstract}
Project alliance requires all parties to work together in good faith, share project risks, and make unanimous decisions for the betterment of the project. A key feature of successful implementation of a project alliance is a focus on value creation and value for money. This paper proposes a qualitative system dynamics model to specify and explain dynamics of value creation processes in the context of project alliance. By synthesizing the existing literature and reports on project alliancing, this paper identifies four processes that have a strong influence on the value created in the project alliance context: work progression, rework, redesign and innovation, and rescheduling. In addition, we show how these value creation processes are interrelated and evolve over time. The effectiveness of these processes is influenced by the capability and motivation of the project alliance partners to discover works that do not fully utilize the available resources, and make quick decisions to capture these benefits.
\end{abstract}

Keywords: Value creation; Project alliance; System dynamics; Rework; Redesign and innovation; Rescheduling

${ }^{1}$ Corresponding author. Email: farzad.pargar@oulu.fi 


\section{Introduction}

Project management has traditionally focused on delivering outputs with a specific focus on delivering products on time, on budget, and of a defined quality, which is often articulated as adhering to the "iron triangle" (Andersen, 2008). There has been a shift from a sole focus on product creation to a holistic focus on both product and value creation (Winter et al., 2006a), and over the past few years, project scholars have paid more attention to value creation and the realization of benefits to justify the resources deployed in projects (MacDonald et al., 2012; Winter et al., 2006b). In short, value can be generally defined, as the result of a trade-off between benefits ("what you get") and sacrifices ("what you give") in the management of projects (Matinheikki et al., 2016).

A project alliance is a collaborative project delivery form that relies on value for money thinking (MacDonald et al., 2013; Manley et al., 2009). In a project alliance, the key actors of a project (owner, designer, and contractor) bear both positive and negative risks related to the project jointly and follow principles of information accessibility and unanimous decision-making (Jefferies and Rowlinson, 2016; Lahdenperä, 2017). Much of the extant literature on project alliancing is positive in terms of the value-creating results that can be achieved (e.g., Hietajärvi et al., 2017a; Love et al., 2016).

However, the impact of the procedures followed in project alliancing on the success of projects is not fully clear and is often disputed (Hietajärvi et al., 2017b; Merrow, 2011). Arguments and causal relationships often remain independent general principles, although influential factors and impact chains are very diverse. Many alliance features and characteristics contribute to success, while each feature also seems to strengthen the impact of the others (Lahdenperä, 2017). Therefore, the functional connection between the various alliance principles and results should be assessed and clarified, as prior research has not provided systematic and comprehensive descriptions of valuecreation mechanisms and processes of project alliancing. Therefore, insights on how and through what kinds of mechanisms project alliancing produces a valuable project outcome and value for money are needed. 
To increase our understanding of value creation processes in the context of project alliances, it is important to determine which mechanisms should be incorporated in the management of a project alliance to deliver more valuable outputs. The purpose of this paper is to investigate how value creation in a project alliance's implementation phase occurs by using a qualitative system dynamics approach. As project alliances are inherently complex and dynamic, involving multiple feedback processes and nonlinear relationships, a system dynamics approach is particularly suitable for their modeling and for producing an explicit understanding of value creation processes. The system dynamics approach can help managers to achieve a greater understanding of the system by clarifying how value creation processes emerge, change, and unfold over time. Traditional system dynamics applications in project contexts aim to deliver the project as planned and mainly focus on efficient project implementation (Lyneis and Ford, 2007; Ford and Lyneis, 2013).

This paper contributes to current research by presenting a qualitative system dynamic model to explain how an alliance team responds to changes during the project alliance implementation by exploring the interrelations among the identified value creation processes. The model development is based on an analysis of existing literature and reports on project alliancing. This context is unique from the perspective of system dynamics modeling as this stream of research has typically focused on efficiency-based outcomes in project implementation (see Taylor and Ford, 2006; Lyneis and Ford, 2007) and largely dismissed value-based outcomes.

The rest of this paper is organized as follows. First, we review the literature on value creation, project alliance, and the system dynamics approach in project management. Next, the research methodology is presented. Then, the system dynamics model is investigated in detail. We developed a set of causal loop diagrams to explicitly reveal feedback relationships between major processes that influence value creation in the project alliance. Finally, the paper is concluded with a discussion and avenues for further research. 


\section{Literature review}

\subsection{Value creation in project alliances}

The delivery of value is not just an essential requirement of good project management; it defines what project management is. Consequently, early identification and preservation of the elements of value that the project aims to produce defines the success or failure of a project (MacDonald et al., 2013). Delivering value in projects can be approached from at least two perspectives: the dimensions of value and the timeframe of evaluation (MacDonald et al., 2012). This means that value has many dimensions beyond the conventional economic perspective, including social and environmental elements plus intangible deliverables including, for example, quality of relationships, leadership, learning, reputation, and trust (Shenhar et al., 2001). Furthermore, value is generated and can be assessed during the entire lifecycle of a project and is not, therefore, only focused on the benefits delivered during the implementation phase.

Following this thinking, Shenhar et al. (2001) linked the concept of success to delivering value over varying time horizons - in the short term with successful project delivery and in the long term with a positive impact for the customer and the business - and as a means to invest in the future. In turn, Berman (2007) defined business value generated from projects as cost reduction, business growth, maintaining operations (e.g., regulatory compliance), speed, and efficiency. In general, project value can be considered the result of a trade-off between the benefits and sacrifices, and in interorganizational projects, it is co-created in the interactions and collaborations of the project actors (Ahola et al., 2008). In this paper, value is defined from an economic perspective as the quotient of the project product benefits/project costs (adapted from Morris, 2013; Laursen and Svejvig, 2016), where the product benefits can be short-term or long-term and are quantified in monetary terms. A project alliance can deliver value by reducing project cost and/or increasing the project product's benefits. Here, we have excluded the social dimension of value plus intangible value deliverables such as the quality of relationships, leadership, learning, reputation, and trust. 
Project alliancing is a form of collaborative project delivery arrangement that has been most extensively applied in Australian infrastructure and construction sectors (Walker and Lloyd-Walker, 2015). With roots in North Sea oil projects in the early 1990s, in its pure form, project alliancing can be considered an extreme form of relational integration in which the parties form a joint project and work under a joint multi-party contract. Lahdenperä (2009) defined a project alliance as "a project delivery method based on a joint contract between the key actors to a project whereby the parties assume joint responsibility for the design and construction of the project to be implemented through a joint organization, and where the actors share both positive and negative risks related to the project and observe the principles of information accessibility in pursuing close cooperation." In general, project alliancing can be understood as a contracting arrangement between two or more entities who undertake the work cooperatively on a shared risk-and-reward basis for the purpose of achieving agreed-upon outcomes (Jefferies et al., 2014; Love et al., 2011; Walker and Lloyd-Walker, 2015).

Project alliancing also requires significant behavioral and attitudinal changes from the actors. Teambuilding events, reflection sessions, and workshops are used to facilitate socialization within the project (Hietajärvi et al., 2017b). The principles of good faith and trust as well as an open-book approach, open and transparent information sharing, commitment to "no disputes," best-for-theproject unanimous decision-making processes, a no fault-no blame culture, and a joint management structure with joint decision-making are essential features of project alliances (Walker and LloydWalker, 2015). Innovations, project opportunity identification, and creativity are promoted throughout the project through different kinds of rewarding schemes (Hietajärvi et al., 2017a). Furthermore, co-location of team members in a collaborative space is believed to encourage open communication and cross-functional knowledge sharing (Kokkonen and Vaagaasar, 2018). In project alliances, governance mechanisms such as jointly shared key performance areas that are tied to bonuses and sanctions and monitored throughout the project are used to support the collaboration of 
the project participants in a manner best characterized as "swim or sink together" (Walker and LloydWalker, 2015).

Project alliances also facilitate the application of lean thinking by rewarding cooperation and collaboration between the parties that are actively involved in delivering value (Forbes and Ahmed, 2010). The lean tools and practices, such as Value Stream Mapping, Last Planner System and Target Value Design, are typically used in different phases of project alliance to generate benefits for customers and eliminate waste (Hietajärvi et al., 2017b; Lichtig, 2005). A popular tool that facilitates collaboration in project alliances is co-locational collaborative working environment, "Big Room". In Big Room, the project team is co-located in one place to facilitate the development of a shared collaborative culture and flow of information. Big Room environment and its embedded practices are closely related to Koskela's lean construction philosophy (Koskela and Ballard, 2006) where construction processes are conceptualized as "flows" (Raisbeck et al., 2010). In lean terms, a good flow is a process in which the value stream has the minimum possible non-value-adding works, i.e. the minimum possible waste (Sacks, 2016).

\subsection{System dynamics in project management}

System Dynamics (SD), introduced by Forrester (1961), is an approach to presenting and analyzing the behavior of a complex system in order to achieve a better understanding of what exactly occurs in the process. Project management applications have been the most successful in using system dynamics in terms of number of applications, consulting revenues, and value to clients (Lyneis et al., 2001). System dynamics has proven to be an effective methodology to explain the reasons for project failure and to provide insights for best practice in project management (Rodrigues, 2001). System dynamics has long been applied to understanding and improving project management, beginning with groundbreaking work in a dispute between Ingalls shipbuilding and the U.S. Navy (Cooper, 1980; Lyneis and Ford, 2007; Sterman, 2000). Dynamic models of projects help us to understand the dynamics of disruptions and their impacts, such as late customer changes, delays in design or 
construction approvals, labor and materials bottlenecks, inadequate coordination, and communication between suppliers and customers throughout the project (Sterman et al., 2015).

Project management decisions are often considered strategic, tactical, or operational decisions (Lyneis et al., 2001). Traditionally, the critical path method, the program evaluation and review technique, mathematical programming techniques, and heuristics have been employed to solve project management decision problems at the operational level (Wang and Liang, 2004). However, the majority of project failures relate to strategic issues of project management including planning the project, determining measurement and reward systems, evaluating risks, and learning from past projects (Lyneis et al., 2001). Project managers have used informal mental models based on their own experience and vision of reality to support strategic decision-making (Rodriguez and Bowers, 1996). System dynamics models facilitate the strategic management of projects by considering decisions that are made up-front in designing the project and by providing guidance about operational decisions that consider the long-term impact of these decisions on downstream performance of the project (Lyneis et al., 2001). With the growing complexity of projects, strategic project management has become increasingly crucial to project success (Rodriguez and Bowers, 1996). Traditional tools and mental models are inadequate for dealing with the dynamic complexity of projects. These tools and concepts either view a project statically or take a partial, narrow view to allow managers to mentally cope with the complexity (Lyneis et al., 2001).

The application of system dynamics to project management can be divided into three categories: project structure, project dynamics, and project domain (Ford and Lyneis, 2013). Generic project structures that capture project dynamics, such as the rework cycle and the feedback mechanisms related to rework and productivity, have been developed over the years. Lyneis and Ford (2007) divided the structures underlying project dynamics into four groups: project features, rework cycle, project control, and ripple and knock-on effects. System dynamics has a long history of investigating 
the role of feedback loops in project models (e.g., Godlewski et al., 2012; Jalili and Ford, 2016; Taylor and Ford, 2006).

Wang et al. (2017) presented a system dynamics model of a project monitoring and control system to evaluate the value realization of ongoing projects under uncertainty. They showed that a threshold for remedial actions should be used to avoid overreactive behavior leading to escalation and a waste of resources. Project domain accounts for project management practice across a wide range of domains and for several purposes (see, for example, the application of SD modeling to construction projects [Nasirzadeh and Nojedehi, 2013] and information technology projects [Zawadzki, 2009]). Comprehensive surveys of system dynamics literature on project management can be found in Rodrigues and Bowers (1966), Lyneis and Ford (2007), and Sterman et al. (2015).

\section{Research methodology}

System dynamics is a methodology that is typically used to understand the behavior of a complex system over time (Sterman, 2000). SD is also used as a methodology for system description and modeling (Wolstenholme and Coyle, 1983). It focuses on cause and effect relations, analyzes various decision scenarios and feedback loops, observes trends of system components in different time frames, finds improvement policies, and ultimately achieves a better understanding of the system (Sterman, 2000; Lyneis and Ford, 2007). These features make SD modeling a suitable approach to study the dynamics of value creation in the project alliance context, which requires a systematic and holistic approach capable of capturing feedback loops.

Several authors have suggested that simulation and modeling can be used as a tool for theory development (Davis et al., 2007). The main argument for using the SD modeling for theory development is that it requires explicit definitions of the complex relationships between theoretical constructs. It also enables the analysis of multiple interdependent processes, which often results in nonlinear system behavior (Harrison et al., 2007). Rudolph and Repenning (2007) used SD modeling 
as a theory development tool to examine how an organizational system responds to an ongoing stream of non-novel interruptions to existing plans and procedures. Repenning and Sterman (2001) also developed a theory using an SD simulation model to examine how corporate capability is developed through process improvement.

In this paper, a qualitative system dynamics approach was selected for the development of a process theory on value creation in the project alliance context. Process theories explain patterns in events, activities, and choices and increase understanding of how things evolve over time and why they evolve in this way (see Van de Ven and Huber, 1990). Process research takes time and sequence into account and provides explanations of the sequence of events leading to an outcome (Langley, 2009). This project's theory development effort with qualitative SD modeling is based on an analysis of existing literature and reports on project alliancing. Its purpose is to move toward a general explanation of how an alliance team responds to changes during project alliance implementation and to explore the interrelations among the identified value creation processes.

There are different symbolic systems such as verbal argumentation in natural languages or formal languages such as mathematical equations to describe theories (Edmonds and Mayer, 2013). In this paper, we do not create propositions or mathematical equations, but we apply causal loop diagrams (CLD) to describe the dynamics of value creation. The CLD is a system dynamics modeling tool that helps to map the cause-and-effect relationships among variables (Sterman, 2000). The description of system behavior using CLDs is an important part of developing dynamic models (Coyle, 2000) and has been suggested as a method of describing how complex systems develop over time (Langley et al., 2013). This modeling tool is an appropriate method to convey the results of this study and to explore the causalities, loops, and feedback effects in the system.

CLDs consist of words or phrases that are linked by curved arrows, each of which has attached polarity and time delay symbols. An arrow between two variables represents a causal relationship between them. The polarity is symbolized by '+', indicating that the two related variables change in 
the same direction, or '-', showing that the two linked variables vary in two different directions. The arrows can compose circular causality and develop into two types of feedback loops, either reinforcing loops $(\mathrm{R})$ with exponentially growing/decaying behavior or balancing loops (B) with goal-seeking behavior. These feedback loops, as a closed sequence of cause and effects, are one of the practical forms of process theories (Langley, 2009). The interactions among different loops determine the final behavior of the system. For an in-depth description, please see Sterman (2000).

\section{Model development}

\subsection{Project alliance phases and practices}

A project alliance is typically divided into selection, development, and implementation phases. Figure 1 illustrates the main tasks and outcomes of the different phases. In the selection phase, the client/owner(s) forms the alliance by selecting partners from the tendering consortiums. The price is not the key selection criterion, and partners who are capable of working together will be chosen with an emphasis on competence and technical capacity (Lahdenperä, 2009). In the development phase, the alliance members work jointly under a common organization to make decisions related to the project's overall scope and meet the client/owner's value for money criteria. The development phase is facilitated by the development of joint alliance practices such as open knowledge sharing, brainstorming, innovation workshops, and cooperative behaviors (Alliance Executive Team, 2014). At the end of the project development phase, commercial model and implementation plans will be approved.

A commercial model aligns project participants' behaviors toward the achievement of a project's key performance targets through the use of incentive scheme (Love et al., 2010). The core of the commercial model of the project alliance is a multidimensional incentive scheme which requires key performance targets as an input. In the development of the commercial model, contracting parties agree on an exact target outturn cost (TOC) prior to construction of the project and, after the 
completion of the project, the owners and service providers share the difference between the TOC and the realized costs - an under-run or over-run (Lahdenperä, 2015). The commercial model of the project alliance is not limited to a cost incentive targeted at the TOC and it includes performance incentives set for other key performance targets such as schedule, quality, and project benefits such as usability and public image. A bonus (direct monetary value) will be paid for performance that exceeds the minimum requirement, while a sanction will be charged for performance falling short of it. Incentives allow for better alignment of the contracting parties' goals to serve the interests of the overall project (Lahdenperä, 2009). The result of the development phase provides the basis for the implementation phase.

\begin{tabular}{|c|c|c|}
\hline Selection Phase & Development Phase & Implementation Phase \\
\hline $\begin{array}{l}\text { Forming of the alliance } \\
\text { - Preliminary plans and design proposals } \\
\text { - Tenderer selection using evaluation } \\
\text { criteria } \\
\text { - Set up the alliance }\end{array}$ & $\begin{array}{l}\text { Project planning and design } \\
\text { - Develop commercial model (gain/pain sharing) } \\
\checkmark \text { Define key performance targets, including: } \\
\text { target outturn cost and lead time, quality, } \\
\text { safety, usability, and public image } \\
\checkmark \text { Define a multidimensional incentive scheme } \\
\text { - Develop alliance practices and collaborative } \\
\text { culture, including: } \\
\checkmark \text { Communication and interaction agreement } \\
\checkmark \text { Innovation and joint problem-solving }\end{array}$ & $\begin{array}{l}\text { Delivery of services } \\
\text { - Implement the agreements } \\
\text { - Monitor targets and manage changes: } \\
\checkmark \text { Management of uncertainties } \\
\checkmark \text { Management of ideas and innovations } \\
\checkmark \text { Management of quality issues } \\
\checkmark \text { Management of (non-) value-adding } \\
\quad \text { works }\end{array}$ \\
\hline $\begin{array}{l}\text { Selection of the best parties by } \\
\text { competence, capacity, and tender price }\end{array}$ & \multicolumn{2}{|c|}{$\begin{array}{ll}\text { Definition of the project's scope and client's value for money } & \text { Implementation of tasks and creating value to } \\
\text { criteria. Developing alliance capability and motivation. } & \text { meet the alliance's targets }\end{array}$} \\
\hline
\end{tabular}

\section{Figure 1. Main tasks and outcomes at different project alliance phases.}

The project implementation phase, which is the focus of this study, is not a trivial task, even after careful planning in the development phase (Wang et al., 2017). Project contingency factors such as uncertainty and complexity influence value creation processes. Systematic approaches to describing value creation processes in regard to all the complex and dynamic conditions of the project alliance are still lacking. In this paper, the project complexity level is characterized by dependency among tasks (Lu et al., 2015). In the context of high task complexity (i.e., number, variety, and interrelationships), deviations from the plan in any task influence the overall project implementation.

It is also important to realize that many different sources and types of uncertainties exist during the project implementation phase (Pruyt, 2007). Uncertainty related to product features and working 
methods provides opportunities for innovation to redesign product features to increase product benefits or to decrease project implementation costs. The discovery of more feasible innovative solutions in the development phase will reduce innovation opportunities in the implementation phase and this could reduce project uncertainty related to product features and working methods. Uncertainty may also result in unplanned changes that result in the need to reschedule work and flexibly reassign resources. To ensure that the project product is completed as planned, there is also a need for effective mechanisms to detect and correct errors that are made during the implementation phase.

By synthesizing existing literature on project management and project alliances, this paper proposes a qualitative system dynamics model by identifying four distinct but interrelated processes that have a strong influence on the value created in project alliance. The developed model divides the value creation of the project alliance implementation system into four processes: (1) work progression, (2) rework, (3) redesign and innovation, and (4) rescheduling. Descriptions of these value creation processes are provided in Table 1 . These value creation processes will be discussed in detail when describing CLDs in the following subsections.

Table 1. Description of value creation processes

\begin{tabular}{ll}
\hline $\begin{array}{l}\text { Value creation } \\
\text { processes }\end{array}$ & Description and impact on value creation \\
\hline $\begin{array}{l}\text { Work progression } \\
\text { process }\end{array}$ & $\begin{array}{l}\text { Basic process to complete work as defined in project plans and } \\
\text { adjust work rate to meet targets }\end{array}$ \\
Rework process & $\begin{array}{l}\text { This process minimizes work completed incorrectly through } \\
\text { discovery and correction of errors } \\
\text { - Increases product benefits relevant to project quality issues by } \\
\text { correcting errors }\end{array}$ \\
$\begin{array}{l}\text { Redesign and } \\
\text { innovation process }\end{array}$ & $\begin{array}{l}\text { This process maximizes the redesign of product features such as } \\
\text { usability, safety, and public image } \\
\text { - Increases product benefits by redesigning product features } \\
\text { - Reduces project costs by redesigning working methods and } \\
\text { removing unnecessary task }\end{array}$
\end{tabular}



and increasing resource utilization

The effectiveness of these processes is influenced by the capability and motivation of alliance partners to discover work completed incorrectly, opportunities to improve product features or decrease project costs, and work that needs rescheduling to mitigate cost related to changes in project plans, as well the efficiency of decision-making processes to capture these benefits.

Based on alliance literature, alliance capability and motivation together with the speed of decisionmaking facilitate the value creation processes and affect how the project alliance manages and coordinates tasks during the project implementation phase. We define alliance capability and motivation as the ability (collective strengths) and willingness of alliance partners to discover tasks that are not fully utilizing resources and to share relevant information with other partners. Alliances can deliver a more valuable product through the discovery and correction of work completed incorrectly, work with potential for innovation, and non-value-adding work. A high level of alliance capability is related to a high degree of the alliance's resource endowments and the joint forces to pursue project values that are otherwise beyond reach (see Das and Teng, 2002). A high level of alliance motivation is related to a high alignment in partners' preferences, interests, and practices in an alliance (see Hardy and Phillips, 1998; Kogut, 1989).

In addition to capability and motivation, the speed of decision-making is another important factor in delivering value in projects. If the alliance has enough capability and motivation to discover nonvalue-adding works but does not make best-for-project decisions quickly enough, the opportunity for correcting non-value-adding works (e.g., error, waiting) will be lost. Quick decision-making is related to both high degrees of communication and information sharing among partners and project alliance team authority to make decisions without external permits. In an alliance context, practices such as 
Last Planner workshops and co-location of the project team in one place (Big Room concept) improve the coordination of daily work and speed of decision-making processes (Hietajärvi et al., 2017b).

Alliance practices and collaborative culture are dynamic in nature throughout the life of an alliance (Doz, 1996). Alliance capability and motivation are likely to improve slowly in the formation and development phases as the partners collaborate and bring in valuable resources and design the incentive scheme (see Das and Teng, 2002). Alliance capability is an asset that accumulates the results of improvement programs (i.e., alliance practices) over time and must be developed within the project team (Aaltonen and Turkulainen, 2018; Repenning and Sterman, 2001). Motivation is another asset that is aligned through the incentive system in project alliances. According to Scheublin (2001), the success of project alliances is strongly related to the fact that no party can increase profit by shifting cost to another party, and this motivates parties to cooperate. In the project alliance, alliance capability and motivation are significant predictors of alliance performance (Heimeriks and Duysters, 2007; Hietajärvi et al., 2017b). Depending on alliance performance in the development phase, there will be an initial level of capability and motivation at the beginning of the implementation phase. An important challenge for alliance teams is to sustain and consistently drive collaborative culture in the implementation phase (Rooney, 2009; Ross, 2009).

In this study, we modeled processes that have a strong influence on value creation in the project alliance implementation phase and explain how they dynamically evolve over time. To fulfill the research aim, we first developed a set of CLDs to specify and explain value creation processes in the project alliance. This model evolved from well-established SD models including those developed by Ford and Sterman (1998) and Lyneis and Ford (2007). Table 2 provides a summary of the loops of each value creation process and a brief description of them. The resulted causal loop diagram shows 10 feedback loops. Three loops are reinforcing (positive loops) and the other seven are balancing (negative loops). The interactions among different loops determine the system's final behavior. For 
readers familiar with system dynamic simulation, we have also provided stock-flow diagrams of the value creation processes in the Appendix.

Table 2. Value creation processes and their feedback loops.

\begin{tabular}{|c|c|c|}
\hline Value creation processes & Loops & Descriptions \\
\hline \multirow{2}{*}{$\begin{array}{l}\text { Work progression } \\
\text { process }\end{array}$} & B1 & The effect of schedule pressure on productivity \\
\hline & B2 & The effect of schedule pressure on resource level \\
\hline \multirow{4}{*}{ Rework process } & R1 & The effect of schedule pressure on error generation \\
\hline & $\mathrm{R} 2$ & The effect of undiscovered rework on quality \\
\hline & B3 & The effect of cost pressure on rework reduction \\
\hline & B4 & $\begin{array}{l}\text { The effect of rework decision on undiscovered error } \\
\text { reduction }\end{array}$ \\
\hline \multirow[t]{2}{*}{$\begin{array}{l}\text { Redesign and innovation } \\
\text { process }\end{array}$} & B5 & $\begin{array}{l}\text { The effect of innovative solutions to redesign project } \\
\text { features on product benefits }\end{array}$ \\
\hline & B6 & The effect of removing unnecessary works on project cost \\
\hline \multirow[t]{2}{*}{ Rescheduling process } & R3 & $\begin{array}{l}\text { The effect of disruptions and changes on work } \\
\text { waited/wasted }\end{array}$ \\
\hline & B7 & $\begin{array}{l}\text { The effect of rescheduling inexecutable works on work } \\
\text { waited/wasted }\end{array}$ \\
\hline
\end{tabular}

\subsection{Work progression process}

Project alliance consists of a collection of tasks that should be performed during the implementation phase. The project alliance team seeks to deliver the project according to the agreed key performance targets by the end of the implementation phase. It is important to model the controlling feedback loops through which the project alliance team attempts to close the gaps between project performance and key performance targets. One common project alliance practice is to control the ability to meet the deadline. The completion of work (rate of work progress), assuming perfect quality, depends on available resources and productivity. Productivity measures the efficiency of work progression. In the work progression process, we used two common actions in the project management context: working faster and increasing resources (based on Lyneis and Ford, 2007).

An alliance may decide to accelerate the project by aggressively scheduling activities, thereby allowing less time to complete each activity. This is known as schedule pressure. Schedule pressure is the tension caused by the gap between the project alliance team's perception of the required time 
to complete the project with the originally allocated resources and the actual time left before the planned completion date (Yaghootkar and Gin, 2012). Extensive analyses of the dynamic effects of schedule pressure on project performance can be found in Nepal, Park, and Son (2006).

Another managerial action of the project alliance team for project control is to employ additional resources to close the gaps between project performance and targets. Many of the unintended side effects of this action have already been identified and studied in the literature (Taylor and Ford, 2006; Lyneis and Ford 2007; Godlewski et al., 2012). In this research, we assumed that alliance partners assign resources with enough experience to ensure the success of the project. Therefore, we avoided including the well-studied side effects of additional resources such as congestion, workforce experience, and the effect of experience on productivity.

Figure 2 shows the effect of schedule pressure on productivity and the resource level in the two balancing loops. Please see Taylor and Ford (2006) and Lyneis and Ford (2007) for more detailed descriptions of the loops in Figure 2. Here, we highlighted the effect of alliance capability, motivation, and speed of decision-making on the loops explained below. In the work progression process, we focused on the positive side of work quality in generating work completed correctly. The negative side of work quality in generating errors will be discussed along with the rework process.

\section{B1: Work faster}

An increase in schedule pressure leads to a higher intensity of work and faster completion of work (which increases productivity). Therefore, work rate, which is the potential working capacity of the project alliance team to perform tasks in each time period, will be increased as well. However, in complex projects, too much pressure can be detrimental to productivity (Nepal et al., 2006). In a project alliance where the level of project complexity is high, the need for coordination will be increased and resources (i.e., people) can spend more time performing tasks if the capability and motivation to coordinate work is at a sufficiently high level. 


\section{B2: Add resources}

Increasing the resource level will increase work rate, reduce the remaining work, and decrease schedule pressure. The decision to change the resource level depends on the alliance's capability and motivation to share/add resources and delays in the decision-making process. In a project alliance, parties are usually not only motivated to share the resources but are also capable of making this decision quickly to deliver the project on schedule.

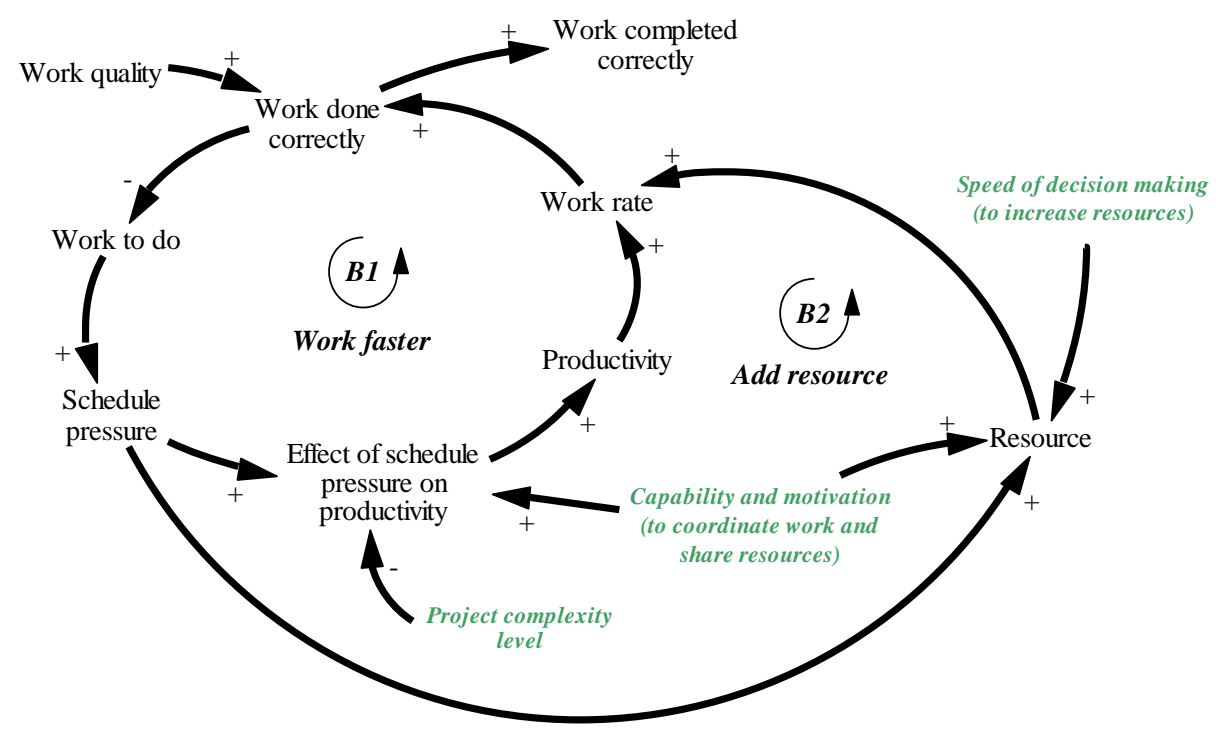

Figure 2. The structure of work progression.

\subsection{Rework process}

In the real world, work is executed with less than perfect quality, errors tend to remain unperceived, and reporting systems overestimate real progress and discourage reporting of rework (Rodriguez and Bowers, 1996; Lyneis et al., 2001). Another common project alliance practice is to control the quality of the project through rework to correct the generated errors. We define project quality in this paper as the fraction of work being done at any point in time that is completed correctly. We assumed that every error could not be discovered and corrected during the project implementation phase and that a fraction of the work is completed incorrectly. Rework is a major contributor to schedule delays and 
cost overruns, and almost all dynamic project models have a rework cycle in some form (Love and Edwards, 2004; Lyneis et al., 2001).

The discovery of errors and their correction is the core of the rework process. Errors are detected in the normal course of work and as the result of downstream efforts or testing (Lyneis, Cooper, and Els, 2001). The error generation rate, which is dependent on work quality, determines how much work is defective. This defective work (errors) must be discovered before it can be corrected, and this is modeled with the discovery of errors rate. In project management literature, the time required to discover rework is the main influencing factor of rework discovery (Cooper, 1993; Rahmandad and $\mathrm{Hu}, 2010)$. However, discovering errors and correcting them is dependent on the alliance's ability and willingness to monitor and reveal the information relevant to the errors and their efficiency in decision-making. Many system dynamics project management models are based on a version of the "rework cycle," which distinguishes four states of project work: work to do, work completed, undiscovered rework, and rework to do (Cooper, 1993).

In this study, we have introduced two new states called "known errors" and "work completed incorrectly" to better explain how the alliance's capability, motivation, and speed of decision-making impact the effectiveness of the rework process. Work completed incorrectly is the result of delays in both the discovery of errors and deciding to correct errors. If the alliance's capability, motivation, and speed of decision-making are low, then the alliance cannot discover the errors and correct them on time and the work will be completed incorrectly (chance of correcting errors will be gone). By the end of the project, the fraction of work completed incorrectly can be used as a measurement tool for project quality.

Figure 3 shows the effects of two reinforcing loops (R1-R2) and two balancing loops (B3-B4) on the rework process. The loops R1, R2, and B4 have been studied in the literature (Ford and Sterman, 2003; Cooper, 1994; Lyneis et al., 2001). However, we highlighted the effect of project complexity level and alliance capability, motivation, and speed of decision-making in these loops. 


\section{R1: Haste makes waste}

Schedule pressure is the most common reason for decreased quality of work and generating errors (Ford and Sterman, 2003). If there is a large penalty for missing the deadline, the project will be more sensitive to delays and the project team will be under more pressure to get the project back on schedule (Jalili and Ford, 2016). In a project with a high level of complexity, schedule pressure results in outof-sequence work and subsequently generates even more errors. This is due to the high level of dependency among tasks and physical or information constraints in complex projects. The discovery of generated errors due to low work quality and efficiently deciding to correct them leads to less work completed incorrectly, thereby increasing product benefits relevant to quality and safety issues. However, the decision to correct errors increases the amount of work to do and subsequently could decrease work quality through higher schedule pressure.

\section{R2: Errors on errors}

Undiscovered errors in upstream work can propagate and be inherited in later work, which reduces the quality of downstream work and leads to more errors (Lyneis et al., 2001). In a very complex project, due to a high level of dependency among tasks, the effect of undiscovered errors on quality will be greater. The project complexity can also decrease the chance of discovering errors in the upcoming period. Therefore, more errors will be undiscoverable (work completed incorrectly due to failure to discover errors) and work quality will be further decreased as a consequence of reduction in prior work quality.

\section{B3: Rework reduction}

Rework can extend project duration, workload, and cost far beyond the original plan. According to Love and Edward (2004), rework, on average, contributes to $52 \%$ of total budget overrun and can increase schedule overrun by $22 \%$. To minimize the negative consequences of rework, we considered schedule pressure and cost pressure as influencing factors to reduce the rate of correcting errors. 
When the schedule and cost pressures are high, it might be beneficial for project alliance team to reduce the correction of errors and subsequently reduce the product quality. This balancing loop can be used by the alliance team to control resourcing on the project and deliver value for money.

\section{B4: Rework decreases errors}

All generated errors during project implementation have the potential to turn into work completed incorrectly. However, if the project alliance team has the capability and motivation to discover errors and makes decisions to correct them fast enough, the undiscovered errors will be reduced. By reducing the undiscovered errors, the alliance will be able to reduce the effect of errors on errors and increase product quality.

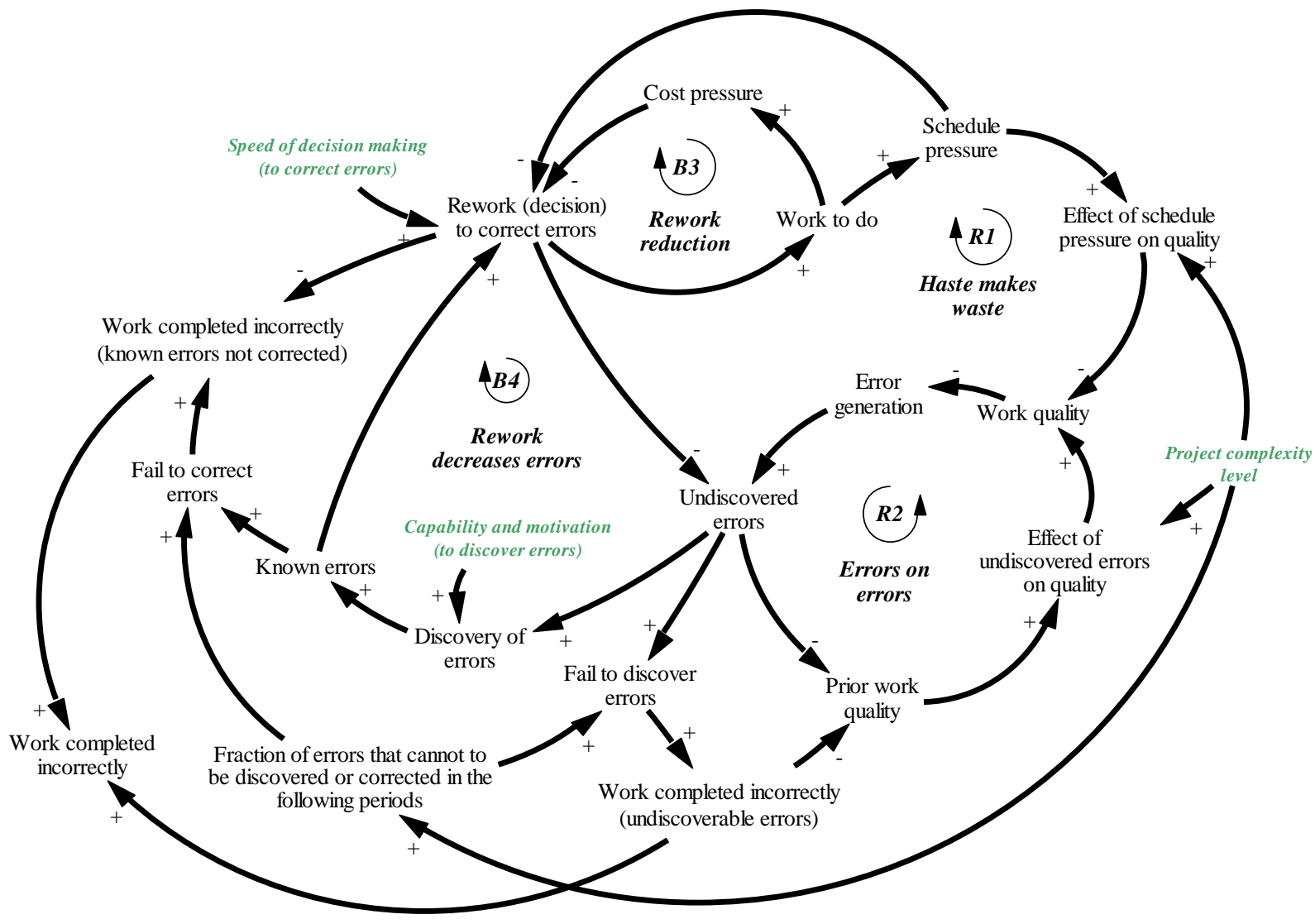

Figure 3. The structure of the rework process.

\subsection{Redesign and innovation process}

The framework of a project alliance facilitates the promotion of innovative design and construction techniques as well as the development of new managerial practices and processes (Lorenti and 
McWilliam, 2005). One of the key features of project alliances is a focus on collaboration and knowledge integration arrangements among the partners that supports innovative outcomes and behaviors (Manley et al., 2009). By involving the contractor at an early stage of the design process, the alliance will be able to deliver complex product systems with innovative solutions under uncertain conditions (Lahdenperä, 2017). In some projects, only a small percentage of the ideas discovered during the development phase are further prioritized and put into practice due to the fact that some ideas are aimed at unrealistic savings (Alliance executive team, 2018). Taking advantage of a collaborative alliance environment in the development phase minimizes the requirement for redesigning work features during the implementation phase. However, due to the uncertainty related to product features and working methods, all potential innovative solutions cannot be discovered during the development phase and there still exist opportunities for innovation in the implementation phase (Debarro et al., 2015).

The innovation process can decrease the cost of the project by introducing more efficient work methods or by eliminating non-value-adding work such as inventory time, transportation time, and set-up time. The innovation process can also increase the product benefits by increasing the usability of the product and safety-related targets of the project by redesigning work features. Changes in design often create additional problems (e.g., delay and disruption) by significantly altering project execution sequences and/or resource profiles (Sterman, 2000; Han et al., 2013). If the project alliance is not capable of a systematic implementation of new ideas and updating the schedule, redesigning product features and working methods and putting them into practice may cause changes in the weekly schedule. Implementing change is often disruptive and involves short-term costs before longterm benefits are realized (Lyneis, Cooper, and Els, 2001).

Communication between parties with different skillsets and efficient decision-making are important for the development of innovative solutions. The implementation of innovations may be slowed down or hindered when decisions require approval from outside the project. For example, in the 
Rantatunneli project alliance (see Alliance executive team, 2018), contaminated soil from the tunnels could not be put back into the railway structure due to challenges with obtaining permits. Figure 4 shows two main loops affecting the redesign and innovation process.

B5: Innovation increases product benefits

This loop shows the effect of redesigning product features and working methods through innovative solutions on the benefits and costs of the project. In the implementation phase, there still exist innovation opportunities to increase the benefits of the project by redesigning product features. As the capability and motivation of the alliance to discover innovative solutions increase, the number of known innovative solutions will also increase. Then, by making redesign decisions quickly, the alliance can efficiently use the available opportunities to improve product features and increase product benefits. In this loop, schedule pressure negatively influences redesign decisions to improve product features, as these decisions may be perceived to increase project duration and workload.

B6: Innovation decreases project costs

More known innovative solutions provide more redesign opportunities to improve working methods and remove unnecessary tasks (e.g., meetings). Unnecessary tasks generate costs but do not add value to the product, and by removing them, the project cost will decrease. 


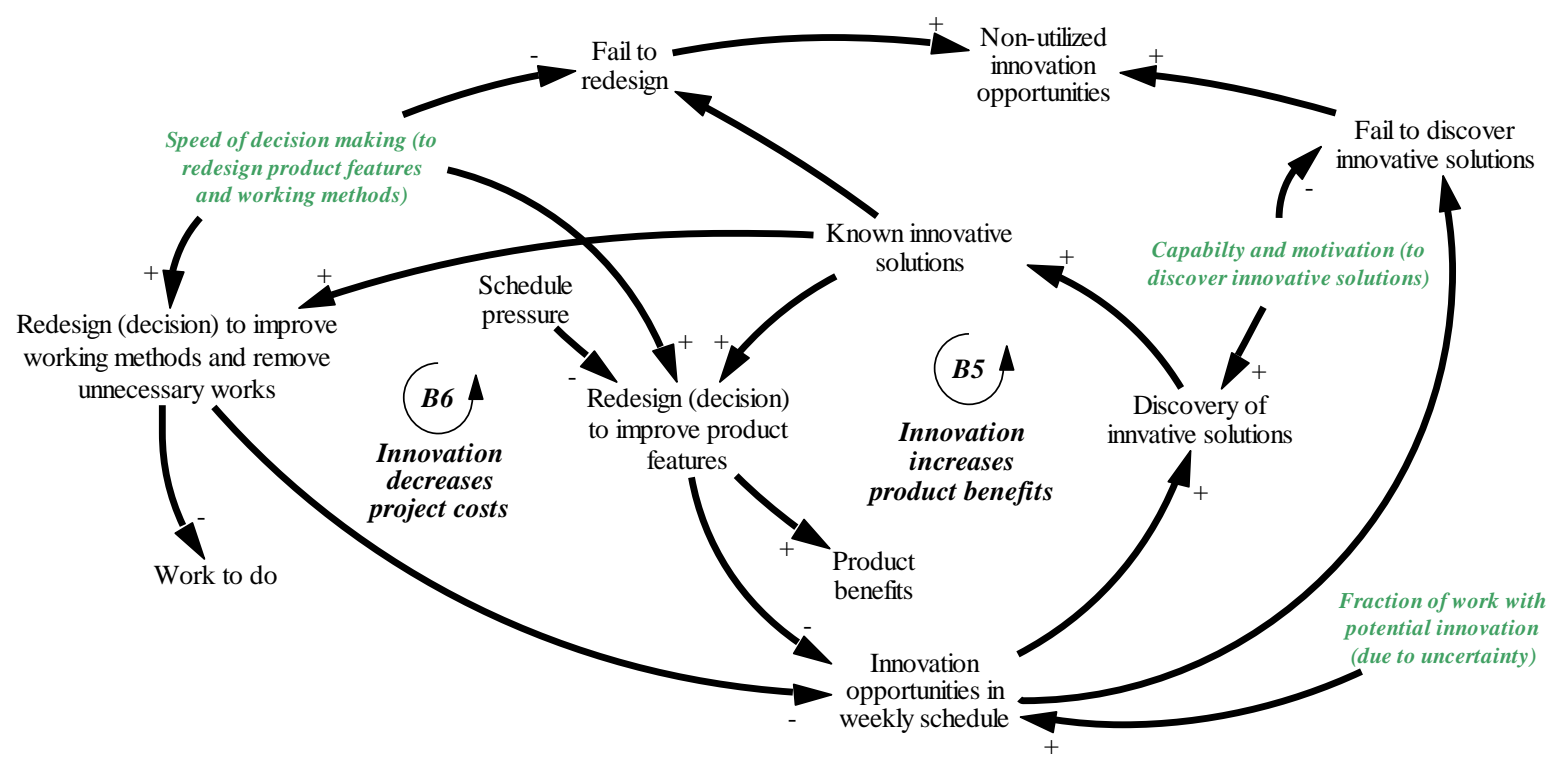

Figure 4. The structure of the innovation process.

\subsection{Rescheduling process}

Rescheduling is the process of updating an existing project schedule or work to be done in response to disruptions or other changes (Vieira at al., 2013). Disruptions relate to project uncertainty in terms of social, technical, economic, environmental, and political risks (Boateng et al., 2013) that influence the project schedule. During the project implementation phase, changes in design, error correction, and issues related to subcontracting, outsourcing, and the environment (e.g., heavy rain) increase the need for rescheduling. In any of these situations, maintaining the initial schedules instead of generating new practical schedules leads to inexecutable tasks, idle resources, and delays, which are known as wastes (Green, 1999; Koskela, 2000). Therefore, any change during project execution usually requires rescheduling to adjust project tasks and resources and avoid wastes (Liu and Shih, 2009). When there are no disruptions and changes, tasks can be progressed normally in work progression process without the need for rescheduling.

The inexecutable work in each period is also known as non-value-adding work, which takes time and resources without delivering any benefits (Koskela, 2000). The project alliance team can prevent inexecutable work in each time period by discovering work that needs to be rescheduled and making 
quick decisions to reschedule them. If the alliance partners have the capability to discover non-valueadding work and the motivation to share relevant information and make fast rescheduling decisions, they can utilize the available working capacity efficiently. Figure 5 shows two main loops affecting the rescheduling process.

R3: Disruptions and changes increase work waited/wasted

This loop shows the effect of disruptions and other changes (i.e., rework and redesign) on generating inexecutable work. If the alliance's capability, motivation, and speed of decision-making are not sufficiently high, then inexecutable work due to changes and disruptions cannot be discovered and replaced by executable work. By failing to discover inexecutable work and reschedule it, the resources will be idle and more work will be waited/wasted. This initiates more changes in the upcoming period due to work not executed in the previous period. In a project with a high level of complexity, rework and redesigning product features result in an increased need to reschedule the existing plan.

B7: Rescheduling decreases work waited/wasted

As the capability and motivation of the alliance to discover inexecutable work increase, the number of known inexecutable tasks will also increase. Then, by improving the coordination of tasks and making fast rescheduling decisions, the alliance can efficiently use the available work rate and reduce work waited/wasted. Rescheduling can reduce project costs by increasing resource utilization and replacing inexecutable work. 


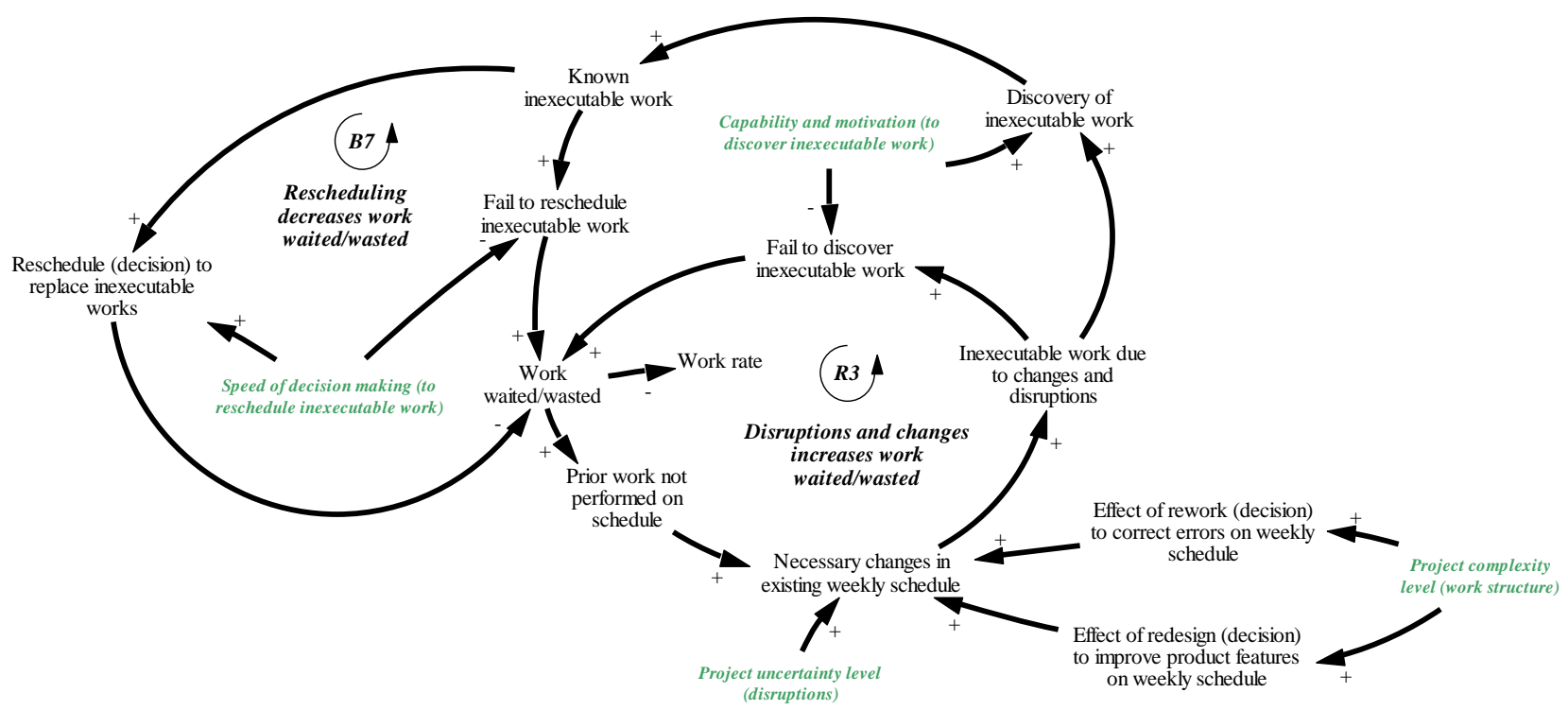

Figure 5. The structure of the rescheduling process.

4.6. Interrelations among the processes and their impact on value creation

In managing a complex project alliance including tight time constraints and high risk and uncertainty, incorporating all the processes yields to more valuable outputs. Project alliance team can respond to changes during project implementation through rework, redesign and innovation, and rescheduling processes for getting the most out of the resources. A project alliance can deliver a valuable output by increasing product benefits and decreasing project costs through the discussed value creation processes. The rework and redesign processes increase the product benefits by minimizing the work completed incorrectly and maximizing the redesign of product features, respectively. The redesign and rescheduling processes decrease the project costs by maximizing the removal of unnecessary work and maximizing resource utilization. The decision to rework or redesign causes some changes in weekly plans that impact the rescheduling process. Although changes and disruptions are the main causes of wastes (Hampson and Mohamed, 2002), the relevant risks can be mitigated in a project alliance with good practices and collaborative culture due to fast decision-making and information sharing. A project alliance can deliver value for money even in very complex and uncertain projects by having high capability, motivation, and speed of decision-making. In this paper, we have excluded the discussion on the importance of each process in comparison with other processes. More research 
is required to better understand how their relative importance could be project case specific and influenced by the commercial model.

Figure 6 summarizes the interrelations among the work progression process (work rate adjustment), rework process (correction of errors), redesign and innovation process (redesign product features and removal of unnecessary work), and rescheduling process (reschedule inexecutable work) in general by removing the impact of alliance characteristics and project contingency factors. Figure 6 also illustrates several managerial actions for controlling to meet key performance targets. Four common actions can be taken to correct a situation in which the project alliance team forecasts time and cost overrun: increase work capacity by adding more resources or work faster, reduce redesigns of product features that can lead to inefficient use of resources due to work waited/wasted, reduce rework by accepting work completed incorrectly, and slip deadline as a last resort to solve the schedule pressure problem and update the whole plan by rescheduling the previous tasks not performed on schedule.

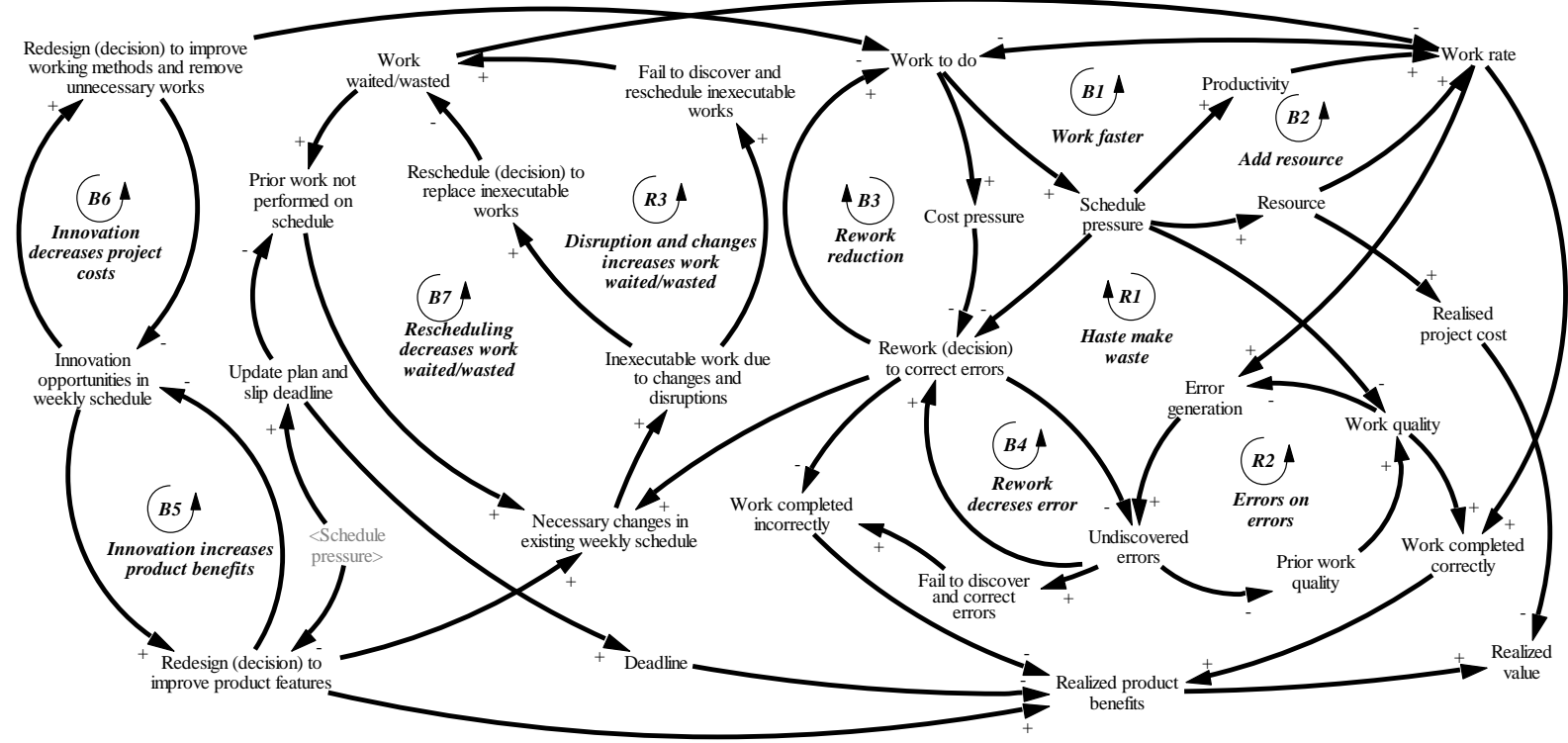

Figure 6. The interrelations among processes and their impact on value creation. 


\section{Conclusions}

\subsection{Theoretical implications}

Recent evidence has suggested that project alliances are an effective way to manage and deliver complex projects and to create value in uncertain project contexts (Lahdenperä, 2017; Suprapto et al., 2016). However, the majority of studies have focused on static assessments of the characteristics, practices, outcomes, and benefits of project alliances (Walker and Lloyd-Walker, 2015). The main contribution of the present study is that it extends our understanding of the dynamics of value creation in the context of project alliances by identifying and describing distinct value creation processes and explicating their interrelations through the development of a system dynamics model.

The developed model suggests that value in the alliance project implementation phase is created through four distinct but interrelated processes: adjust work rate to complete work as defined in project plans (work progression process), increase product benefits by reducing negative impact of errors (rework process), increase product benefit and reduce project costs by redesigning product features and working methods (redesign and innovation process), and reduce inexecutable work to mitigate cost related to changes in project plans (rescheduling process). Alliance capability and motivation to discover tasks that are not fully utilizing available resources and to share relevant information together with the speed of decision-making facilitate the value creation processes and ensure that the project's value creation goals are met. The resulting model is capable of explicitly revealing feedback relationships between factors that influence value creation in the project alliance context. Consequently, the value of our contribution comes particularly from combining the system dynamics approach with research on project alliances.

While traditional system dynamics applications in project contexts aim to deliver the project as planned, the generated model accounts for the flexibility and incorporation of changes even during the project implementation phase, which is central for value creation. Consequently, we contribute to the literature on system dynamics modeling in the project context (Lyneis and Ford, 2007; Ford and 
Lyneis, 2013) by shifting the focus from efficient project implementation to value creation. We identify redesign and rescheduling processes and integrate them with the known rework process to capture more value during project implementation. We also include new features in the rework process by modeling delays in both discovery of rework and making the decision to correct errors, which results in work completed incorrectly. The generated model also advances prior research on how value is created in projects (Ahola et al., 2008) from an economic perspective by focusing on an alliance setup and explicitly defining and conceptualizing the different elements and processes associated with value creation in this context. The resulting model systematically examined the interplay of value creation processes and identified issues that influence the value created in projects.

\subsection{Managerial implications}

Alliancing is not suitable for every project, and it is important to understand when to utilize alliancing. Selecting an appropriate project delivery method is dependent on the project characteristics, contingency factors, and the owner's needs and preferences (Khalil, 2002). Collaborative project management practices such as project alliance have been suggested as a solution for managing projects with tight time constraints and cost control, high risk and uncertainty, need for innovation, large projects with multiple/complex stakeholders, complex external threats, and environmental challenges (Chen et al., 2012; DoIRD, 2015; Cocks et al., 2011). The results indicate how and through which processes an alliance can create value. The developed model suggests that managers look beyond a single process and that any decision they make may have significant side effects. For example, a decision to improve product design may influence other tasks and cause a change in the project schedule. A failure to reschedule work will lead to work wasted and decreased resource utilization. Project complexity increases these effects, as a change in design affects many other tasks.

The results also indicate that the potential benefits from the value creation processes are realized by the alliance partners' increased capability and motivation to achieve the project goals "to create value 
for money." In addition, there is a need for effective decision-making practices to ensure that decisions are made quickly enough to capture the potential benefits and mitigate negative consequences of deviations from the plan. The design of a commercial model, selection of alliance practices used in the project, and development of collaborative alliance culture should be tailored based on their influence on alliance capability, motivation, and speed of decision-making. These decisions are typically made in the development phase of the project, but the effectiveness of different practices should be continuously monitored throughout the implementation phase.

The system dynamics approach can help managers to achieve a better understanding of the system by clarifying how value creation processes emerge, change, and unfold over time. System dynamics model also help the managers to understand the long- and short-term consequences of actions. The findings of the study imply that managers and members of alliance projects need to be aware of changes in the project implementation phase and adjust their managerial approaches accordingly. They need to develop the ability to discover changes, increase motivation to share information about these changes with other partners, and improve the speed of making best-for-project decisions to deliver valuable outputs.

In summary, project delivery models such as project alliance and any specific managerial practices should be selected in consideration of the project context. A system dynamics model can be used to support managers by analyzing the impact of different managerial practices on value creation processes and, ultimately, the value created by the project.

\subsection{Limitations and further research}

This study contributes to project management literature by modeling the value creation dynamics in a project alliance. The developed CLD model is subject to some limitations. We assumed that alliance capability, motivation, and speed of decision-making do not change during the implementation phase. 
More research is required to better understand how factors such as schedule pressure, realized value, expected incentive, and different alliance practices influence the development of capability and motivation of alliance partners and their decision-making processes.

Our focus was on value creation processes in the implementation phase of project alliance. An extension of this model could also consider value definition processes in the development phase. A simulation model that would cover the entire lifecycle of a project could be used, for example, to analyze the impact timing to move from the development phase to the implementation phase. In modeling value creation dynamics, we have not provided a comprehensive perspective on dimensions of value. All the benefits generated from projects cannot properly quantified in monetary terms. Therefore, extending the proposed model by considering social dimension of value plus intangible value deliverables should be further explored.

The generalizability of the model in terms of explaining value creation in non-alliance projects should also be further explored. Future studies could benefit from using case study data and further validating our findings. Another direction for future research is to empirically examine the qualitative system dynamic model presented in this paper, paying specific attention to the consequences of managerial actions during different phases of project implementation.

We suggest that the value creation processes and their interrelationships described using CLDs be considered the first step to developing a process theory of value creation in a project alliance context. This proposed model will be used as a basis for developing a stock and flow model of the system dynamics method. By developing a stock and flow simulation model, we can analyze the impact of project contingency factors such as project complexity, uncertainty, and time criticality on value creation processes. This requires further analysis of the project characteristics and quantifying monetary terms of delivering benefits and implementation costs. Simulation results can also demonstrate the importance of alliance partners' capability, motivation, and efficient decisionmaking processes to create value for money. 
Appendix. Stock-flow diagram

Figure A presents all formerly discussed causal loops in terms of a stock and flow diagram.

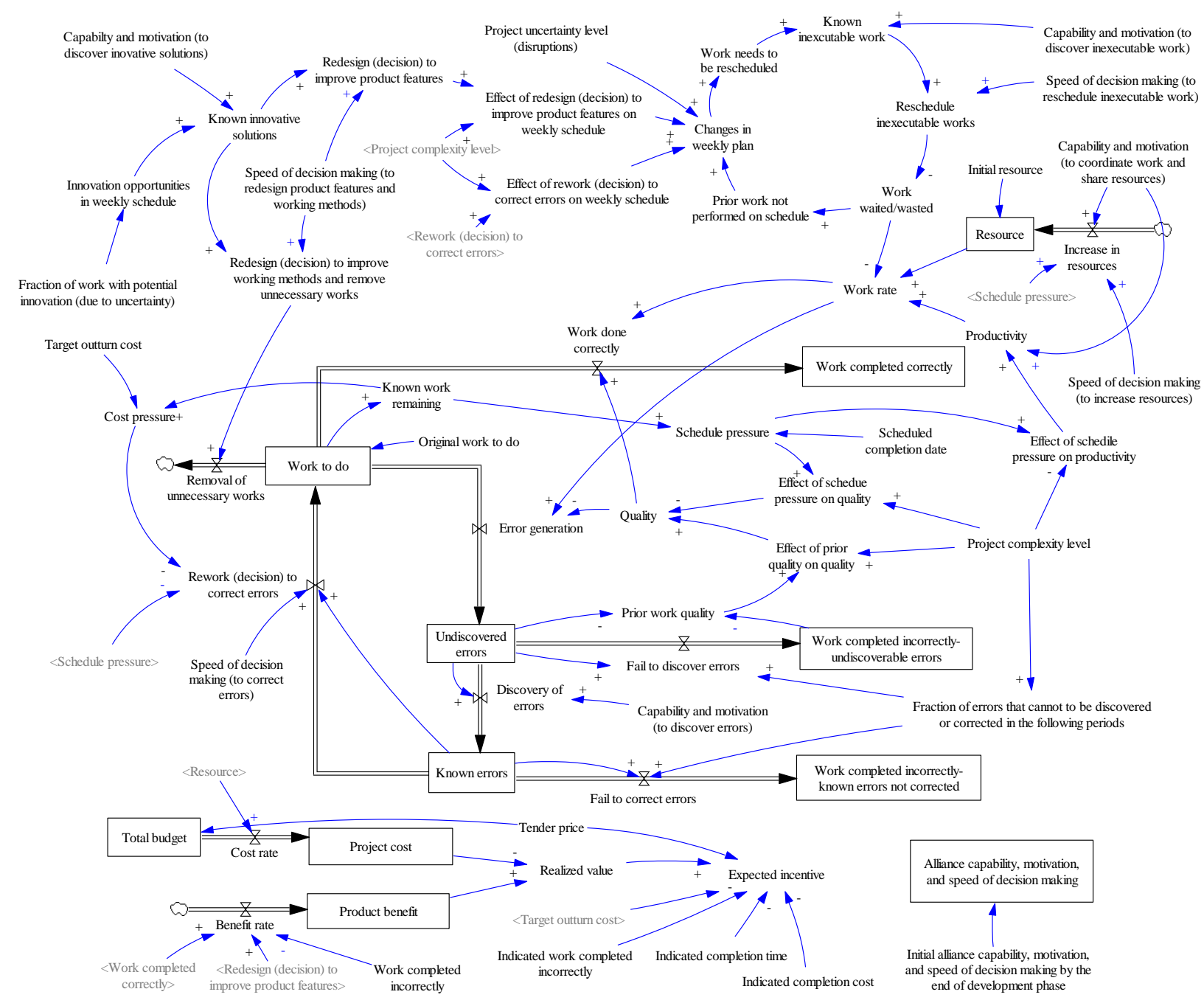

Figure A. Stock-flow diagram of all value creation processes.

\section{Acknowledgments}

The authors gratefully thank the anonymous reviewers for their constructive remarks. We also thank participants at the 2018 System Dynamics conference for their comments and suggestions. 
References

Aaltonen, K., Turkulainen, V., 2018. Creating relational capital through socialization in project alliances. International Journal of Operations and Production Management, 38(6), 1387-1421.

Ahola, T., Laitinen, E., Kujala, J., Wikström, K., 2008. Purchasing strategies and value creation in industrial turnkey projects. International Journal of Project Management, 26(1), 87-94.

Alliance Executive Team, 2014. Rantatunneli alliance project. Value for money report, project development phase. Tampere City, Finnish Transport Agency, Lemminkäinen Infra, Saanio and Riekkola, A-Insinöörit Suunnittelu, Tampere.

Alliance Executive Team, 2018. Rantatunneli alliance project. Value for money report, project implementation stage.

Andersen, E.S., 2008. Rethinking project management: an organisational perspective. FT Prentice Hall, Essex, England.

Barlas, Y., 1996. Formal aspects of model validity and validation in system dynamics. System Dynamics Review, 12(3), 183-210.

Berman, J., 2007. Maximizing project value: defining, managing, and measuring for optimal return. AMACOM Div American Mgmt Assn.

Boateng, P., Chen, Z., Ogunlana, S., Ikediashi, D., 2013. A system dynamics approach to risks description in megaprojects development. Organization, Technology and Management in Construction: An International Journal, 4(Special Issue).

Che Ibrahim, C.K.I., Costello, S.B., Wilkinson, S., 2013. Development of a conceptual team integration performance index for alliance projects. Construction Management and Economics, 31(11), 1128-1143.

Chen, G., Zhang, G., Xie, Y.M., Jin, X.H., 2012. Overview of alliancing research and practice in the construction industry. Architectural Engineering and Design Management, 8(2), 103-119.

Cocks, G., Scott, J., Pearce, T., Hazebroek, M., Fisher, P., Wilson, R., 2011. Delivery of low-volume road in Pilbara region of western Australia by alliance contracting. Transportation Research Record: Journal of the Transportation Research Board, 2203, 203-210.

Cooper, K.G., 1993. The rework cycle: benchmarks for the project manager. Project Management Journal, 24(1), 17-21.

Coyle, G., 2000. Qualitative and quantitative modeling in system dynamics: some research questions. System Dynamics Review, 16(3), 225-244.

Davis, J., Eisenhardt, K., Bingham, C., 2007. Developing theory through simulation methods. Academy of Management Review, 32(2), 480-499.

DeBarro, T., MacAulay, S., Davies, A., Wolstenholme, A., Gann, D., Pelton, J., 2015. Mantra to method: lessons from managing innovation on Crossrail, UK. In Proceedings of the Institution of Civil Engineers-Civil Engineering, 168(4), 171-178.

DoIRD, 2015. National alliance contracting guidelines guide to alliance contracting, Department of infrastructure and regional development editor. Commonwealth of Australia.

Doz, Y.L., 1996. The evolution of cooperation in strategic alliances: Initial conditions or learning processes. Strategic Management Journal, 17(S1), 55-83.

Edmonds, B., Meyer, R., 2013. Introduction to the Handbook. In Simulating Social Complexity. Springer, Berlin, Heidelberg.

Forbes, L.H. and Ahmed, S.M., 2010. Modern construction: lean project delivery and integrated practices. Crc Press.

Ford, D.N., Lyneis, J.M., 2013. Applying System Dynamics to Project Management. Virtual issue of System Dynamics Review. Available: https://onlinelibrary.wiley.com/page/journal/10991727/homepage/VirtualIssuesPage.html\#Appl ying [April 2018]. 
Ford, D.N., Sterman, J.D., 2003. The Liar's Club: concealing rework in concurrent development. Concurrent Engineering, 11(3), 211-219.

Forrester, J., 1961. Industrial Dynamics. MIT Press, Cambridge, MA.

Godlewski, E., Lee, G., Cooper, K., 2012. System dynamics transforms fluor project and change management. Interfaces, 42(1), 17-32.

Green, S.D., 1999. The missing arguments of lean construction. Construction Management and Economics, 17(2), 133-137.

Harrison, R., Carroll, G., Carley, K., 2007. Simulation modeling in organizational research. Academy of Management review, 32(4), 1229-1245.

Hietajärvi, A.M., Aaltonen, K., Haapasalo, H., 2017a. Opportunity management in large projects: a case study of an infrastructure alliance project. Construction Innovation, 17(3), 340-362.

Hietajärvi, A.M., Aaltonen, K., Haapasalo, H., 2017b. What is project alliance capability. International Journal of Managing Projects in Business, 10(2), 404-422.

Jalili, Y., Ford, D.N., 2016. Quantifying the impacts of rework, schedule pressure, and ripple effect loops on project schedule performance. System Dynamics Review, 32(1), 82-96.

Jefferies, M.C., Rowlinson, S., 2016. New Forms of Procurement: PPP and Relational Contracting in the 21 st Century. Routledge.

Khalil, M.I., 2002. Selecting the appropriate project delivery method using AHP. International Journal of Project Management, 20(6), 469-474.

Kohtamäki, M., Rabetino, R., Möller, K., 2018. Alliance capabilities: A systematic review and future research directions. Industrial Marketing Management, 68, 188-201.

Kokkonen, A., Vaagaasar, A.L., 2018. Managing collaborative space in multi-partner projects. Construction Management and Economics, 36(2), 83-95.

Koskela, L., 2000. An exploration towards a production theory and its application to construction. VTT Technical Research Centre of Finland.

Koskela, L. and Ballard, G., 2006. Should project management be based on theories of economics or production?. Building Research \& Information, 34(2), 154-163.

Lahdenperä, P., 2009. Project alliance. The Competitive Single Target-Cost Approach. VTT Tiedotteita-Research Notes, 2472.

Lahdenperä, P., 2015. The beauty of incentivised capability-and-fee competition based target-cost contracting. Procedia Economics and Finance, 21, 609-616.

Lahdenperä, P., 2017. Towards a coherent theory of project alliancing: Discovering the system's complex mechanisms yielding value for money. Construction Economics and Building, 17(2), 41-61.

Langley, A., 2009. Studying processes in and around organizations. The Sage handbook of organizational research methods, 429.

Langley, A., Smallman, C., Tsoukas, H., Van de Ven, A., 2013. Process studies on change in organization and management: unveiling temporality, activity, and flow. Academy of Management Journal, 56(1), 1-13.

Laursen, M., Svejvig, P., 2016. Taking stock of project value creation: A structured literature review with future directions for research and practice. International Journal of Project Management, 34(4), 736-747.

Liu, X., Zeng, M., 2017. Renewable energy investment risk evaluation model based on system dynamics. Renewable and Sustainable Energy Reviews, 73, 782-788.

Lichtig, W.A., 2005. Sutter health: Developing a contracting model to support lean project delivery. Lean Construction Journal, 2(1), 105-112.

Lloyd-walker, B. M., Mills, A. J., Walker, D. H., 2014. Enabling construction innovation: the role of a noblame culture as a collaboration behavioural driver in project alliances. Construction Management and Economics. 32(3), 229-245. 
Lu, Y., Luo, L., Wang, H., Le, Y. and Shi, Q., 2015. Measurement model of project complexity for large-scale projects from task and organization perspective. International Journal of Project Management. 33(3), 610622.

Lyneis, J. M., Cooper, K. G., Els, S. A., 2001. Strategic management of complex projects: a case study using system dynamics. System Dynamics Review. 17(3), 237-260.

Lyneis, J. M., \& Ford, D. N., 2007. System dynamics applied to project management: a survey, assessment, and directions for future research. System Dynamics Review. 23(2-3), 157-189.

Lorenti, L., McWilliam, T., 2005. Project Alliancing and Innovation.

Love, P.E. and Edwards, D.J., 2004. Forensic project management: The underlying causes of rework in construction projects. Civil Engineering and Environmental Systems. 21(3), 207-228.

Love, P. E., Teo, P., Davidson, M., Cumming, S., Morrison, J., 2016. Building absorptive capacity in an alliance: Process improvement through lessons learned. International Journal of Project Management. 34(7), 1123-1137.

Love, P.E., Davis, P.R., Chevis, R. and Edwards, D.J., 2010. Risk/reward compensation model for civil engineering infrastructure alliance projects. Journal of Construction Engineering and Management, 137(2), 127-136.

MacDonald, C., Walker, D.H. and Moussa, N., 2012. Value for money in project alliances. International Journal of Managing Projects in Business. 5(2), 311-324.

MacDonald, C., Walker, D.H. and Moussa, N., 2013. Towards a project alliance value for money framework. Facilities. 31(5/6), 279-309.

Manley, K., McFallan, S., Kajewski, S., 2009. Relationship between construction firm strategies and innovation outcomes. Journal of Construction Engineering and Management. 135(8), 764-771.

Matinheikki, J., Pesonen, T., Artto, K., Peltokorpi, A., 2017. New value creation in business networks: The role of collective action in constructing system-level goals. Industrial Marketing Management. 67, 122133.

Matinheikki, J., Artto, K., Peltokorpi, A. and Rajala, R., 2016. Managing inter-organizational networks for value creation in the front-end of projects. International journal of project management, 34(7), 1226-1241.

Merrow, E.W., 2011. Industrial megaprojects: concepts, strategies, and practices for success. John Wiley \& Sons.

Morris, P.W., 2013. Reconstructing project management. John Wiley \& Sons.

Nasirzadeh, F., Nojedehi, P., 2013. Dynamic modeling of labor productivity in construction projects. International Journal of Project Management. 31(6), 903-911.

Nepal, M.P., Park, M. and Son, B., 2006. Effects of schedule pressure on construction performance. Journal of Construction Engineering and Management. 132(2), 182-188.

Pruyt, E., 2007, August. Dealing with uncertainties combining system dynamics with multiple criteria decision analysis or with exploratory modelling. In Proceedings of the 25th International Conference of the System Dynamics Society.

Rahmandad, H., Hu, K., 2010. Modeling the rework cycle: capturing multiple defects per task. System Dynamics Review. 26(4), 291-315.

Raisbeck, P., Millie, R. and Maher, A., 2010. Assessing integrated project delivery: a comparative analysis of IPD and alliance contracting procurement routes. Management, 1019, 1028.

Richardson, G. P., Pugh III, A. I., 1981. Introduction to system dynamics modeling with DYNAMO. Productivity Press Inc.

Repenning, N.P. and Sterman, J.D., 2001. Nobody ever gets credit for fixing problems that never happened: creating and sustaining process improvement. California management review. 43(4), 64-88.

Rodrigues, A. G., 2001. Managing and modeling project risk dynamics a system dynamics-based framework. In Fourth European Project Management Conference, 1-7.

Rodrigues, A., Bowers, J., 1996. The role of system dynamics in project management. International Journal of Project Management. 14(4), 213-220.

Rudolph, J.W. and Repenning, N.P., 2002. Disaster dynamics: Understanding the role of quantity in organizational collapse. Administrative Science Quarterly. 47(1), 1-30.

Sacks, R., 2016. What constitutes good production flow in construction?. Construction management and economics, 34(9), 641-656.

Scheublin, F.J.M., 2001. Project alliance contract in The Netherlands. Building Research \& Information. 29(6), 451-455. 
Shenhar, A.J., Dvir, D., Levy, O. and Maltz, A.C., 2001. Project success: a multidimensional strategic concept. Long range planning. 34(6), 699-725.

Sterman, J.D., 1992. System dynamics modeling for project management. Unpublished manuscript, Cambridge. MA, 246.

Sterman, J.D., 2000. Business dynamics: system thinking and modeling for a complex world, Boston: The McGraw- Hill Companies, Inc.

Sterman, J., Oliva, R., Linderman, K. W., Bendoly, E., 2015. System dynamics perspectives and modeling opportunities for research in operations management.

Suprapto, M., Bakker, H.L.M., Mooi, H.G., Hertogh, M.J.C.M., 2016. How do contract types and incentives matter to project performance, International Journal of Project Management. 34(6), 1071-1087.

Taylor, T., Ford, D. N., 2006. Tipping point failure and robustness in single development projects. System Dynamics Review. 22(1), 51-71.

Taylor, T. and Ford, D.N., 2006. Tipping point failure and robustness in single development projects. System Dynamics Review: The Journal of the System Dynamics Society. 22(1), 51-71.

Van de Ven, A.H. and Huber, G.P., 1990. Longitudinal field research methods for studying processes of organizational change. Organization Science. 1(3), 213-219.

Vieira, G.E., Herrmann, J.W. and Lin, E., 2003. Rescheduling manufacturing systems: a framework of strategies, policies, and methods. Journal of Scheduling. 6(1), 39-62.

Vilasini, N., Neitzert, T., Rotimi, J., 2014. Developing and evaluating a framework for process improvement in an alliance project: a New Zealand case study. Construction Management and Economics. 32(6), 625640.

Winter, M., Andersen, E.S., Elvin, R., Levene, R., 2006a. Focusing on business projects as an area for future research: an exploratory discussion of four different perspectives. International Journal of Project Management. 24, 699-709.

Winter, M., Smith, C., Morris, P., Cicmil, S., 2006b. Directions for future research in project management: the main findings of a UK government funded research network. International Journal of Project Management. 24, 638-649.

Walker, D.H.T. and Lloyd-Walker, B.M., 2015. Collaborative Project Procurement Arrangements, Project Management Institute, Newtown Square, PA.

Wang, L., Kunc, M., Bai, S. J., 2017. Realizing value from project implementation under uncertainty: An exploratory study using system dynamics. International Journal of Project Management. 35(3), 341-352.

Wolstenholme, E.F. and Coyle, R.G., 1983. The development of system dynamics as a methodology for system description and qualitative analysis. Journal of the Operational Research Society. 34(7), 569-581.

Yaghootkar, K. and Gil, N., 2012. The effects of schedule-driven project management in multi-project environments. International Journal of Project Management. 30(1), 127-140.

Zawadzki, T., 2009. Applying system dynamics modeling to IT project management. IFAC Proceedings. 42(13), 152-157. 